\title{
The Conception and Research of Civil Aviation College Education Reform Based on Employment
}

\author{
Qi Qi ${ }^{1, a}$, Honghu Jiang 2, b \\ ${ }^{1}$ Guangzhou Civil Aviation College, Guangzhou 510403, China; \\ ${ }^{2}$ National Defence of Industry Press, Beijing 100048, China. \\ aqiqi@caac.net, b228651816@qq.com
}

\begin{abstract}
This paper propose the civil aviation college education reform goals by analysis CAAC's (Civil Aviation Administration of China) \& MOE's (Ministry of Education of China) documents and educational reform practice of guangzhou civil aviation college. The author explain the problem from three aspects, the first is strengthen student training for teaching upgrade; the second is enhancing school-enterprise cooperation for multi-dimensional support for student training; the third is emphasizing the quantity and quality of practical courses for student training. Finally, the author provide suggestion from five aspects of unity, efficiency, quantity, leverage and practice.
\end{abstract}

Keywords: Employment orientation; Civil aviation Higher Vocational Education; keywords covered; Innovative ideas of teaching reform; Implementation path; School and enterprise cooperation.

\section{以就业为导向民航高职院校教改构想及路径初探}

\section{綦琦 ${ }^{1}$, 江洪湖 $^{2}$}

\section{1. 广州民航职业技术学院, 广州 中国;}

\section{2. 国防工业出版社, 北京 中国}

摘 要: 本文分析民航局和教育部文件, 以广州民航学院教改实践为参考, 阐述了以就业为导 向的民航高职院校教改明确目标。分别从强化人才培养工作的内涵建设为办学升级夯实基础、 增进校企合作强化产学研对人才培养工作的多维度支撑、通过重视校内实训课程的数量和质 量提高人才培养质量三个方面深入解析了以就业为导向的民航高职院校教改创新型构想。最 后，分别从协同、高效、量化、借力、务实五个方面阐述了民航高职院校教改实践的具体路 径方案。

关键词：就业导向；民航高职；教改创新思路；实施路径；校企合作

\section{1. 前言}

早在 2008 年，民航局党组提出 “持续安全、大众化、全球化” 的民航强国战略，并将之作为 推进我国由世界民航大国向民航强国蜕变的重要抓手。2012 年国务院颁布《关于促进民航业 发展的若干意见》，其中明确指出民航业是我国经济社会发展重要的战略产业。2014 年，为 了响应十八届三中全会提出全面深化改革的战略部署, 教育部领导在全国职业教育工作会议 上做了题为 《加快构建以就业为导向的现代职业教育体系，为促进经济提质增效升级提供人 才支撑》的讲话。根据《国务院关于加快发展现代职业教育的决定》和教育部《高等职业教 育创新发展行动计划（2015-2018 年）》的相关文件精神。广州民航职业技术学院（以下简 称：广航院）作为民航直属行业院校和国家示范性高职院校，兼具服务民航强国战略和引领 高职教育创新的双重使命。从 “十三五” 发展规划构想和创建 “省一流高职院校” 的行动上 看，广航院正在理论探索并创新实践着基于民航行业标准的高技能人才培养路径，力争为民 
航强国和地方经济持续培育出更多符合行业要求、助力地方发展、体现高职特色的能实现充 分就业的优秀人才。

\section{2. 以就业为导向为民航高职院校教改明确目标}

目前, 我国高等教育人才培养质量和国民经济需求之间的供需矛盾日渐凸显。以广航院为例, 民航企业有大量的用人需求, 但就业时学生普遍存在不想去、去不成的现象, 企业招不到合 适的员工、学生找不到理想的岗位。究其根本原因还在于我国高职院校办学沿袭并习惯了普 通高校 “墨守成规” 采用的以学科体系为导向的人才培养模式, 其后果是培养出的学生无法 达企业岗位要求或不情愿留在岗位。时代在发展, 社会在进步, 广航院发展如不能做到与时 俱进, 就会被兄弟院校甚至非行业院校赶上甚至超越。教学质量是院校发展的生命线, 是人 才培养质量的重要保障, 也是院校核心竞争力形成的基础。因此, 以持续推进广航院的教改 工作为中心，全面提高广航院民航特有专业的教学质量, 刻不容缓、时不我待。

教育部明确指出 “以就业为导向” 是我国高职教育服务国民经济发展、服务行业企业的目标。 就业是结果, 就业的关键在于院校能培养出行业企业需要的人才。院校培养人才的能力归根 结蒂在教学质量。教学工作能切实做紧跟行业企业需要, 以就业为导向的目标也就随之实现。 广航院作为高职院校, 其根本任务是培养面向企业、面向生产和服务一线的实用型人才。同 时作为民航局直属的行业院校, 我院还应紧密围绕民航业大发展对高技能人才的客观要求, 持续为民航一线岗位输送符合行业标准的优秀人才。高度重视并切实加强广航院各专业学生 从事民航岗位群工作的核心就业能力地养成工作，即：以就业为导向为教改目标。

\section{3. 以就业为导向的民航高职院校教改思路}

要实现在有限的在校时间内最大程度的提升学生核心就业能力, 是需要一整套科学、系统、 可行且符合以就业为导向目标的教改思路。以下简要阐述笔者从学院教学实践和高职教育发 展的综合维度对民航高职院校教改思路的创新思考:

2.1. 强化人才培养工作的内涵建设, 为办学升级夯实基础

教学管理是一项复杂的系统工程, 主要包括专业及课程设置、教学计划制定、教学运行管理、 教学质量评价、教学资源开发等内容。广航院作为行业院校还应在教学管理方面充分体现民 航行业特色、尊重人才培养客观规律、对接专业岗位具体要求。要实现以就业为导向, 必须 通过强化校企联合办学和优化教学管理程序等针对性的措施, 加强广航院民航特有专业人才 培养工作的内涵建设。例如: 根据企业最新要求优化课程设置和教学内容, 推动专业间优质 教学资源共享, 创新基于学生体验的教学质量评价办法等, 最终为广航院升级为应用技术型 大学夯实人才培养的能力基础。

2.2. 增进校企合作, 强化产学研对人才培养工作的多维度支撑

“立足民航, 服务地方” 是广航院办学的宗旨。如何更好地利用行业院校更加贴近民航企业 生产实际的优势, 尽快构建起校企深度合作的长效机制是必要的也是迫切的。通过笔者多年 的工作实践, 建议可以在甄选现有校外顶岗实习企业的基础上, 强化与南方航空、深圳航空、 白云机场、深圳机场、中国航信等珠三角民航核心企业的业务部门间战略合作关系, 以具体 可行的产学研项目为纽带, 积极引导我国民航标杆企业参与到广航院教改工作中来, 最大程 度地发挥企业在实习岗位提供、岗位标准导入、教师能力提升、联合项目研究、实训教室建 设等多维度的软硬件支撑作用。

2.3. 通过重视校内实训课程的数量和质量提高人才培养质量

高职院校与普通高校在人才培养目标方面最显著的差异就是前者强调学生的从业技能提升, 而后者专注学生的科研能力培养。学生技能培养是需要实际操练的设备设施和模拟企业的生 产及服务环境作为保障的, 这要求重视校内实训课程数量和校外顶岗实习质量是教改的关键 内容。切实做好校外顶岗实习工作是广航院人才培养的特色, 也充分体现了对学生技能培养 
的重视。近些年, 大部分民航企业要求实习和就业无缝衔接, 这客观地推动了广航院学生就 业端口的前移, 即: 校外顶岗实习面试就是学生初次就业选拔。笔者建议: 应高度重视这一 新趋势, 把第三、四学期学生的核心就业能力养成作为以就业为导向教改的工作重点。这就 倒逼院校要更加关注校内实训课程的作用, 通过政策引导专业教师联合实训教师共同开发符 合企业岗位要求的实训课程, 务必加强各专业校内实训课程的开设数量和教学质量。

\section{4. 以就业为导向的民航高职院校教改路径}

以就业为导向的民航高职院校教改目标已经明确、思路渐已清晰。将其尽快落地, 使之成为 广航院 “十三五” 期间和新一轮大发展的 “原力” 则需要在教改路径上的 “谋篇布局” ，笔 者分别从协同、高效、量化、借力、务实这五个方面简要阐述具体做法:

第一, 协同。建立由主管教学校领导负责, 教务处牵头, 各二级学院参与的广航院以就业为 导向教改工作小组, 以服务好学院发展大局的高度, 重视与其它各职能部门的横向协同关系。 积极推动以就业为导向教改目标和思路在二级学院内师生间的最广泛认同和响应, 采取渐进 的方式逐步改革现行有悖于以就业为导向目标的做法。

第二, 高效。搭建起教务处、二级学院、教研室的纵向以就业为导向教改高效联络通道, 确 保涉及教改内容的各项工作按计划高质量完成。特别是要发挥好二级学院主管教学领导的枢 纽作用, 重视各项教改目标任务在学校教务处宏观管理和各专业教研室微观执行两个层面的 顺畅切换。

第三，量化。考核什么、量化什么才能收获什么。为了将以就业为导向教改工作扎实推进， 笔者认为有必要探索建立起与教改配套的专业教师工作情况量化考核办法, 力争在激发教师 工作主动性和积极性的同时, 实现提升教学质量和培养科研氛围的目标。在平衡各方关切的 基础上制定二级学院教师工作情况量化考核办法, 在配合广航院推进分配制度改革的同时, 为实现以就业为导向的教改创新打下坚实的基础和提供可靠的保障。

第四, 借力。切实加强校企合作的广度和深度, 以扩大企业兼职教师队伍为突破口, 借助行 业协会、航司、机场等院校外部力量, 为以就业为导向的教改创新拓展核心优质资源。以就 业为导向的实质就是以企业需求为中心。广航院的教改创新不应是闭门造车, 而是要面向民 航企业真实需求。笔者建议应尽快建立起互利共赢的校企资源对接和交互流动平台, 并以此 为依托切实为实现教改创新做好软硬件支撑。

第五, 务实。坚持以问题为导向, 务实开展各项工作。路径规划的前瞻性、科学性、可行性 固然重要, 但以何种态度执行计划才是核心和根本。我们要清醒的意识到以就业为导向的教 改创新并非一路坦途, 创新的内在逻辑就是 “发现问题——分析问题——解决问题” 并再发 现新问题并解决之。以就业为导向的教改工作能否顺利如期推进, 需要在广航院内部形成求 真务实之风气, 人人都敢于发现问题、毫不回避问题、勇于解决问题。能以问题为导向, 将 实事求是地解决问题的过程作为教改创新的推动力。

民航运输作为服务型行业, 其发展的根本在于 “人” , 在于能否得到满足行业发展要求的高 技能人才的持续供给。这就必然需要以广航院为代表的民航直属院校勇于承担这一行业发展 赋予其的历史使命。以就业为导向的民航高职院校教改任重而道远, 它关乎着我国民航 “十 三五”期间内涵发展的质量, 也影响着民航强国目标能否如期达成。

\section{References}

[1]. Qi Qi. On constructing civil aviation professional education industry chain. Air Transportation Business. Vol. 208(2007)No.11,p.9-12.

[2]. Qi Qi. Setting up innovative research on Chinese Regional Airport Line Work. Air Transportation Business.Vol.273(2010)No.7,p.8-9. 
[3]. Guangling Ma, Qi Qi, Xiaxin Xu. Civil aviation vocational education practice teaching system innovation research. Civil Aviation Management. Vol. 312(2011)No.12,p.93-96.

[4]. Guangling Ma, Qi Qi, Xinming Song. Reflections on the construction of transportation specialty organizations and activities of civil aviation work in Higher Vocational Colleges. Civil Aviation Management. Vol. 256(2012)No.2,p.94-96.

[5]. Xiaxin Xu, Qi Qi. The practice and exploration of the training of professional skills in the third party teaching evaluation system. The small and medium-sized enterprise management and technology. Management and science and technology of small and medium-sized enterprises. 2014.No.11,p.214-215.

[6]. Xu Xiao, Qing Wan, Qi Qi. The design and practice of online management of post practice in Higher Vocational Colleges. Value Engineering.Vol. 370(2015)No.1,p.258-259.

[7]. Xiaxin Xu, Qi Qi, Lei Xing. Research on innovative development course of international civil aviation ticket sales. Air Transportation Business. Vol. 359(2015)No.4,p.37-38.

[8]. Information on: www.caac.gov.cn

[9]. Information on: www.carnoc.com.cn 